\title{
A survey and comparison of TV white space implementations in Japan, the Philippines, Singapore, the United Kingdom, and the United States
}

\author{
Marc Gelian Ante ${ }^{1}$, James Agustin Molina ${ }^{1}$, Emmanuel Trinidad ${ }^{1,2 *}$ and Lawrence Materum ${ }^{1,3}$ \\ De La Salle University, Manila, Philippines ${ }^{1}$ \\ Don Honorio Ventura State University, Bacolor, Philippines ${ }^{2}$ \\ Tokyo City University, Tokyo, Japan ${ }^{3}$ \\ Received: 08-May-2021; Revised: 16-July-2021; Accepted: 18-July-2021 \\ (C)2021 Marc Gelian Ante et al. This is an open access article distributed under the Creative Commons Attribution (CC BY) License, \\ which permits unrestricted use, distribution, and reproduction in any medium, provided the original work is properly cited.
}

\begin{abstract}
For improving the utilization of the television radio spectrum, different countries worldwide have been testing and implementing White Space Devices (WSDs) that make use of the Television White Space (TVWS). This paper compares the implementations, standards, and regulations of TVWS of different countries, particularly Singapore, the United Kingdom, the United States, Japan, and the Philippines. Comparisons on various points were made, mainly on the spectrum identification technology used, the classifications of their respective WSDs, the frequency range, bandwidth, and transmit power of operation, and the safety standards implemented. Having defined regulations for the use of TVWS would assure investors of the stability and the future of the technology. Furthermore, the commercialization and trials of TVWS to bridge gaps are also reported to show different use cases of TVWS for current and future deployment.
\end{abstract}

Keywords

Regulations, Standards, Television white space, White space devices.

\section{Introduction}

Around the world, people have never been more connected with each other than in the present, attributed to the rise of different wireless communication technologies. These technologies allow the exchange of information without the use of any physical medium. In wireless communications, a portion of the available spectrum resource should be allocated to transmit data. This spectrum is limited; therefore, adequate planning of these bands' allocation is essential so that the effects of congestion and interference by the different spectrum users may be reduced [1]. A recent report forecasts that Internet traffic can grow by over $26 \%$ [2] from mobile devices in parallel with the emergence of intelligent devices. This Internet traffic poses a challenge to improve wireless systems and provide Quality of Service (QoS) reliably. In addressing these challenges, Dynamic Spectrum Access (DSA) is seen as a solution to enhance spectrum management by using the physical layer using cognitive radio and avoiding the command-and-control regulations that limit spectrum availability [3].

*Author for correspondence

780
Various national governments have made their radio spectrum regulations to control the spectrum's planning and allocation [4]. To further enhance the efficiency of the spectrum utilization, the establishment of regulations should be necessary. Previously, these governments handed out exclusive licenses for the sole use of a particular frequency band for a specific purpose. Recently, the use of the "license-exempt" spectrum, or the frequency bands not granted exclusive licenses, has been encouraged, bringing about innovations in wireless technologies, which now carry most of the Internet [4]. The migration of the television broadcast from analog to digital has opened up discussions to utilize the idle spectrum efficiently. The Federal Communications Commission (FCC) ruling has encouraged the unlicensed use of the TV bands [5] to reduce spectrum scarcity. Likewise, regulators begin to authorize the opportunistic access to these bands that follows the emergence of standards [6].

While there is a scarcity in the spectrum available for allocation, their utilization is low. Except for the overcrowded cellular network bands, there is a very low occupancy in a significant amount of the spectrum all the time [7, 8]. For example, according to [4], the 
frequency allocations from $30 \mathrm{MHz}$ to $300 \mathrm{GHz}$ are fully assigned in the United States. However, the spectrum utilization rate of the frequencies assigned has an average spectrum utility of $1 \%$ from $30 \mathrm{MHz}$ to 2.7 GHz in the United States. Similarly, in Singapore, the average spectrum utility is only about $6.5 \%$, from $30 \mathrm{MHz}$ to $7 \mathrm{GHz}$. Both countries' spectrum efficiency can be considered low. Technologies that take advantage of the television white space (TVWS) have been designed to utilize these available spectrum bands fully. TVWSs, or merely white spaces, are portions of the radio frequency band that had been not fully maximized or not used all the time [9]. TVWS, particularly those occupying the Very-High Frequency (VHF) and Ultrahigh (UHF) frequency bands, has a considerable advantage in terms of propagation distance [10]. Using TVWS, its properties can fully be taken advantage of, such as covering longer communication distances and better obstacle penetration [4]. With the advantages mentioned above, TVWS technology can be seen as a potential solution to different problems emerging in wireless communication technology.

While communications systems and standards have been developed to use TVWS [11-17], but rollouts have been few, like those in the United Kingdom (UK) [18-20], the United States (US), Singapore [21,22], the Philippines [23, 24] and have not been compared. This paper aims to compare the implementations of
TVWS among different nations, particularly in Singapore, the United Kingdom, the United States, Japan, and the Philippines. Moreover, Section 2 discusses the methods and approaches the authors have taken to acquire the needed data. Section 3 is the discussion for each part of the comparison table. Additionally, reported commercialization and recent trials and techniques simulation are discussed, and Section 4 concludes this work.

\section{Methods}

In this work, the authors have looked for sources, particularly books, regulations, reports, and other technical documents, that would contain information regarding the different implementations of TVWS in the countries of interest. The language barrier for references not available in English and the lack of more technical literature have proved to be detrimental to the conciseness of this paper. Furthermore, to compare the different usage for each country of interest, the authors gathered news articles and government websites that report the trials and implementation of TVWS with a different usage of the bands. Document selection was made through database searches. Figure 1 shows a Preferred Reporting Items for Systematic Reviews and MetaAnalyses (PRISMA) diagram for the document selection processes.

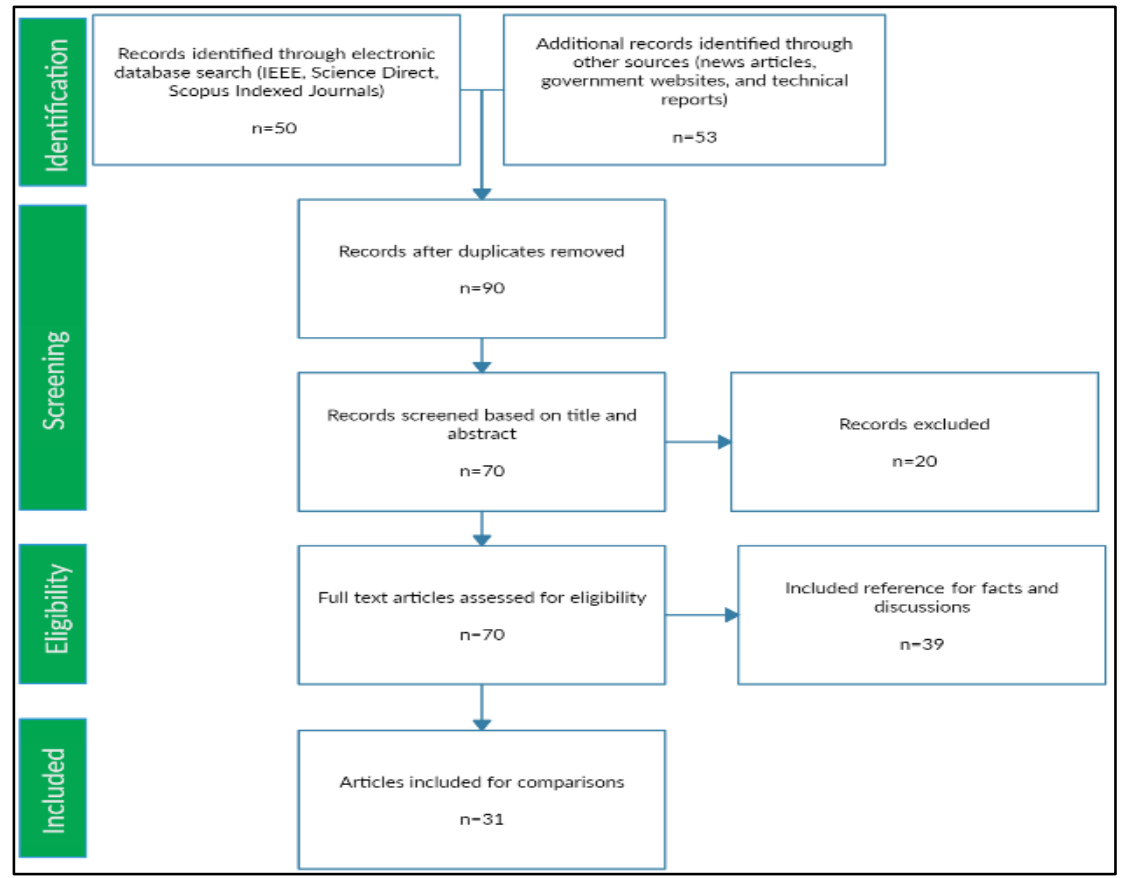

Figure 1 PRISMA Diagram for article screening 
Search strategies were used to limit the search results in both electronic databases and news sources. The authors extracted information from the documents and determine the relevance of the article based on the reports. Moreover, the comparison between information is projected in a table to assess relevant features. Articles have been limited based on the regulations and standards of the selected countries. However, recent relevant articles have been selected with less than five years from publication to have an up-to-date survey of techniques and commercialization. Selected articles show different use cases of TVWS.

\section{Results and discussions}

The section presents the similarities and differences between the implementations of the countries of interest in this paper. Comparisons are made based on the following criteria: spectrum identification, classification of white space device, white space frequency rage, channel bandwidth, transmission power, transmission power, and safety standards for equipment (see Table 1). This section also includes a brief introduction to the regulatory body of each country. The inclusion of recent commercialization and trials is presented in the last part of this section.

\subsection{Regulatory body}

3.1.1Singapore, IMDA

Singapore is one of the most active proponents of the use of TVWS. In June 2014, the authority board, then known as Info-Communications Development Authority (IDA), has released a regulatory framework for TVWS [25]. In October 2016, the current authority board in Singapore, Infocomm Media Development Authority (IMDA), had published the technical standards for TVWS equipment [26], alongside the Telecommunications Standards Advisory Committee (TSAC).

3.1.2The United Kingdom, Ofcom

In 2007, Office of Communications (Ofcom), the United Kingdom's regulating body, proposed using unlicensed devices in the interleaved spectrum of TV bands. Following this, in 2009, they have released consultation and statement reports. These reports contained the proposals and how to determine the necessary parameters of White Space Devices (WSD) to operate on the TV spectrum without interfering with the licensed users [4].

\subsubsection{The United $S$ tates, FCC}

The regulatory body for the United States, the FCC, is the first in the world to propose that the unused TV spectrum bands be available for the use of unlicensed devices. In 2016, the commission released its first report and order to operate these unlicensed devices in the TV band. The second report and order, which determined many details for the unlicensed TVWS operation, was released two years after, in 2008 [4]. 3.1.4Japan, MIC

Japan's regulatory body for TVWS is the Ministry of Information and Communications (MIC). In 2014, MIC organized a field experiment for the National Institute of Information and Communications (NICT) and Hitachi Koksuai Electric Inc. [27].

3.1.5The Philippines, DICT, NTC

The Philippines, through the Department of Science and Technology Information and Communications Technology Office (DOST-ICTO), aimed to provide various public places in the country with a connection to the Internet. It was seen that TVWS is one of the technologies that would result in an increase in connectivity in the country [24]. In 2015, the Department of Information and Communication Technology took the lead implementing agency's role regarding ICT, previously held by the ICTO. The creation of this new nationaldepartment has abolished the ICTO [28].

While the Department of Information and Communications Technology (DICT) is the overall government department that sees through the country's ICT sector, the National Telecommunications Commission (NTC), an attached agency of the DICT, is responsible for the supervision, adjudication, and control of all the telecommunication services in the country [29]. In 2017, the commission released a Memorandum Circular (MC) regarding the use of TV broadcast channels unassigned and unused for secondary users [30]. This MC regulates the said TV broadcast channels for the utilization of TVWS technology.

\subsection{Spectrum identification}

As previously mentioned, the utilization of the available spectrum is low. With TVWS, the primary goal is to more efficiently utilize the spectrum without interfering or causing interferences to licensed users. With that goal in mind, the regulatory bodies have considered three methods to ensure that interference does not occur: beacons, spectrum sensing [31-33], and geolocation database [34].

In the beacon method, TVWS devices can only transmit after having received a control signal. This signal contains information about the vacant channels within their corresponding service areas. However, for this method, beacon infrastructures, which need to be maintained and operated, must be in place. 
WSDs equipped with spectrum sensing can automatically detect unused channels in the spectrum. Using sensing algorithms, the WSD can pick up signals from particular channels, and if it picks up a signal, it avoids transmitting using that channel.

When a WSD queries a Geolocation Database (GLDB) in a given location, it receives information, such as the transmit power, for the possible channels at that particular time and place [35]. Although this method is associated with some issues [34], it addresses the most significant problem that the other two approaches have, the hidden node problem, wherein a WSD might begin transmission on an occupied channel when an obstacle between the WSD and a primary user exists [34].

3.2.1Singapore

Singapore's IMDA has mandated that queries to the GLDB be the primary approach for determining channel availability and power levels [25]. However, Spectrum sensing can be used as a corresponding method, as long as there is no interference given to other users. The WSDB, once receiving the device parameters of the querying device, shall respond with the operational parameters that the WSD uses to configure its transmissions in TVWS operation [26]. 3.2.2The united kingdom

Based on Ofcom's initial consultation and statement reports, a White Space Database (WSDB) is deemed more important than the other methods mentioned for short to medium term. Using WSDB, determining the technical parameters needed by WSDs to utilize the TV band without interfering with the licensed users would be optimized. Spectrum sensing is allowed as well, provided that the WSD meets particular conditions for sensing parameters. The WSDB contains calculations of the frequency and power restrictions that apply to the interference from WSDs to Digital Terrestrial Television (DTT). Ofcom provides these calculations. Relevant changes to the planning of DTT or other services trigger Ofcom to provide updates to the information contained in the WSDB, expected to occur once or twice a year. Geolocated Program Making and Special Events (PMSE) as signments are also provided to the WSDB, with updates of this information scheduled every 3 hours. Ofcom may also provide unscheduled updates to the WSDB, triggered by the interference management process [27].

\subsubsection{The united states}

The FCC uses geolocation and database access for determining channel availability for an unlicensed device. WSDs may use spectrum sensing as well. WSDs that utilize spectrum sensing must comply with some rules, such as demonstrating a high compliance level that the operations must not produce harmful interference [36]. The geolocation capability of fixed and Mode II devices must have an accuracy of $+/-50$ meters of the geographic coordinate. If an installed fixed device has its coordinates already provided during instalment, geolocation capability is not needed. Personal devices activated from the power-off condition must always provide and register their geographic position. Fixed devices must update their database daily at the least, while personal/portable devices must verify their location at least once every minute. Also, a Mode II device is always required to monitor its position once every minute if it moves more than 100 meters [36] and must redetermine channel availability [4].

3.2.4Japan

Japan has developed its WSDBs, basing on the TVWS standards of Ofcom and FCC. These WSDBs successfully passed all the required tests and were therefore included in the list of the qualified databases for the Ofcom TV white space. NICT's database systems are composed of two servers: the database and the application server. The former manages all the datasets that are relevant to the licensed users and the geographical locations. On the other hand, the latter handles the calculation of necessary data, all interactions to the external interfaces that are relevant, and the logging of all events [27].

3.2.5The Philippines

To operate TVWS equipment without interfering with actual TV broadcastings, the ICTO has seen the need for a WSDB to analyze the available TV channels in different locations. Japan's NICT, meanwhile, has been developing WSDBs that comply with the regulations of various countries. With this in mind, the ICTO and NICT signed a Memorandum of Understanding in March 2015, with NICT providing TVWS technologies, particularly WSDB, to ICTO [37].

Issues have arisen, however, on who should operate the WSDB. With no resolution to these issues, the operating channels of WSDs were then "hardcoded" based on the channels given by the NTC [38]. 
Marc Gelian Ante et al.

Table 1 Comparis on of TVWS implementations

\begin{tabular}{|c|c|c|c|c|c|c|c|c|}
\hline & \multicolumn{2}{|c|}{ Singapore } & \multicolumn{2}{|c|}{ The United Kingdom } & The United States & Japan & \multicolumn{2}{|c|}{ The Philippines } \\
\hline $\begin{array}{l}\text { Regulatory } \\
\text { body }\end{array}$ & \multicolumn{2}{|c|}{ IMDA } & \multicolumn{2}{|c|}{ Ofcom } & FCC & MIC & \multicolumn{2}{|c|}{$\begin{array}{l}\text { DICT } \\
\text { NTC }\end{array}$} \\
\hline Website & \multicolumn{2}{|c|}{ https://www.imda.gov.sg/ } & \multicolumn{2}{|c|}{ https://www.ofcom.org.uk/ } & https://www.fcc.gov/ & https://www.tele.soumu.go.jp & \multicolumn{2}{|c|}{$\begin{array}{l}\text { https://dict.gov.ph/ } \\
\text { http://ntc.gov.ph/ }\end{array}$} \\
\hline $\begin{array}{l}\text { Spectrum } \\
\text { Identification }\end{array}$ & \multicolumn{2}{|c|}{ GLDB [25] } & \multicolumn{2}{|c|}{ GLDB $[4,27]$} & $\begin{array}{l}\text { GLDB [36] } \\
\text { Spectrum, Sensing [36] }\end{array}$ & GLDB [27] & \multicolumn{2}{|c|}{$\begin{array}{l}\text { GLDB* [37] } \\
\text { Hardcoded channel [38] }\end{array}$} \\
\hline \multirow{3}{*}{$\begin{array}{l}\text { Whitespace } \\
\text { devices }\end{array}$} & \multirow[b]{2}{*}{$\begin{array}{l}\text { Master } \\
{[25]}\end{array}$} & Fixed [25] & \multirow[b]{2}{*}{$\begin{array}{l}\text { Master } \\
\text { WSD } \\
{[4]}\end{array}$} & \multirow[b]{2}{*}{ Type A/Type B [4] } & Fixed [36] & -- & \multirow{2}{*}{\multicolumn{2}{|c|}{ Base Station [39] }} \\
\hline & & Mode II [25] & & & Mode I [36] & $\begin{array}{ll}\text { Master } & \text { Type A/Type } \\
\text { WSD[27] } & \text { B } \\
\text { Slave } & \\
\text { WSD[27] } & \end{array}$ & & \\
\hline & $\begin{array}{l}\text { Slave } \\
{[25]}\end{array}$ & Mode I [25] & $\begin{array}{l}\text { Slave } \\
\text { WSD } \\
\text { [4] }\end{array}$ & & Mode II [36] & $\begin{array}{l}\text { Analog Sy stem/Digital Sy stem } \\
\text { [40] } \\
\text { Fixed Device/Mobile Device } \\
{[41]}\end{array}$ & \multicolumn{2}{|l|}{ CPE [39] } \\
\hline $\begin{array}{l}\text { WS Frequency } \\
\text { Range (MHz) } \\
\text { See section } 3.4 \\
\text { for discussion }\end{array}$ & $\begin{array}{l}174-188 \\
195-202 \\
209-230 \\
470-534 \\
614-710 \\
718-742 \\
750-774 \\
790-806\end{array}$ & & $\begin{array}{l}470-606 \\
614-782 \\
470-606 \\
614-782 \\
{[4]} \\
\text { [see } T a b\end{array}$ & 3 in Section 3.4) & $\begin{array}{l}54-60 \\
76-88 \\
174-216 \\
470-512 \\
512-602 \\
620-698 \\
512-602 \\
602-608 \\
614-620 \\
620-698 \\
{[27]} \\
\text { (see Table 4 in Section 3.4) }\end{array}$ & $\begin{array}{l}470-790[27] \\
470-710[42]\end{array}$ & $470-698[$ & \\
\hline $\begin{array}{l}\text { Channel } \\
\text { B andwidth } \\
\text { (MHz) }\end{array}$ & $\begin{array}{l}7 \text { (VHF) } \\
8 \text { (UHF) }\end{array}$ & & $8[4,27]$ & & $6[4,36]$ & $\begin{array}{l}8[27] \\
6 \text { for IEEE 802.11af [4] }\end{array}$ & 6 & \\
\hline $\begin{array}{l}\text { Transmission } \\
\text { Power }\end{array}$ & Fixed & $\begin{array}{l}4 \mathrm{~W} \\
(36 \mathrm{dBm})[26]\end{array}$ & -- & $\begin{array}{ll}\text { Master } & \text { Slave } \\
\text { WSD } & \text { WSD } \\
{[4]} & {[4]}\end{array}$ & $\begin{array}{l}1 \mathrm{~W} \text { to } 4 \mathrm{~W} \\
{[27,36]}\end{array}$ & $\begin{array}{l}2.9 \mathrm{~W} \text { based on trial of IEEE } \\
802.22[27]\end{array}$ & $\begin{array}{l}\text { Base } \\
\text { station }\end{array}$ & $\begin{array}{l}28 \mathrm{dBm} \\
{[43]}\end{array}$ \\
\hline & Mode II & $\begin{array}{l}100 \mathrm{~mW} \\
(20 \mathrm{dBm})[26]\end{array}$ & $\begin{array}{l}\text { Type A } \\
{[4]}\end{array}$ & $\begin{array}{l}\text { Maximum of } 4 \mathrm{~W} \\
(36 \mathrm{dBm}) \text {; Power } \\
\text { base in operating }\end{array}$ & $\begin{array}{l}100 \mathrm{~mW} \text { or } \\
40 \mathrm{~mW} \\
{[27,36]}\end{array}$ & $\begin{array}{l}0.97 \mathrm{~W} \text { ( } 12 \mathrm{~m} \text { antenna height) } \\
\text { based on a trial of IEEE } \\
802.11 \text { af [27] }\end{array}$ & $\mathrm{CPE}$ & $\begin{array}{l}26 \mathrm{dBm} \\
{[43]}\end{array}$ \\
\hline & Mode I & $\begin{array}{l}100 \mathrm{~mW} \\
(20 \mathrm{dBm})[26]\end{array}$ & $\begin{array}{l}\text { Type B } \\
{[4]}\end{array}$ & $\begin{array}{l}\text { channel } \\
\text { (see Table-3 and } \\
\text { Table 4) [27] }\end{array}$ & $\begin{array}{ll}\text { Mode } & 100 \mathrm{~mW} \text { or } \\
\text { I } & 40 \mathrm{~mW} \\
& {[27,36]} \\
\end{array}$ & $\begin{array}{l}10 \mathrm{~mW} \text { and } 50 \mathrm{~mW}[40] \\
10 \mathrm{~mW} \text { to } 130 \mathrm{~mW}[41]\end{array}$ & -- & -- \\
\hline $\begin{array}{l}\text { Contour } \\
\text { Mapping }\end{array}$ & -- & & $\begin{array}{l}\text { Geograp } \\
\text { by WSD }\end{array}$ & $\begin{array}{l}\text { ical Pixels computed } \\
\text { [4] }\end{array}$ & $\begin{array}{l}\mathrm{F}(90,50) \text { for digital TV } \\
\text { signal [4], } \mathrm{F}(50,50) \text { analog } \\
\text { TV signals [4] }\end{array}$ & $\begin{array}{l}\text { Geographical Pixels computed } \\
\text { by WSDB [27] } \\
\text { Article 7, Paragraph } 4 \text { of the } \\
\text { Radio Station Licensing } \\
\text { Procedure Rules (Regulation } \\
\text { No. } 15 \text { of the Radio Control } \\
\text { Committee of 1950) [44] }\end{array}$ & -- & \\
\hline $\begin{array}{l}\text { Safety } \\
\text { Standards for } \\
\text { Equipment } \\
\text { (e.g., } \\
\text { Electromagneti } \\
\text { c compatibility } \\
\text { and Radio } \\
\text { Spectrum } \\
\text { Matters) }\end{array}$ & $\begin{array}{l}\text { ETSI EN } \\
\text { IEC CISP } \\
\text { IEC } 60950 \\
\text { IEC } 62368\end{array}$ & $2^{489-1[26]}$ & $\begin{array}{l}\text { TR } 1000 \\
\text { TR } 1000\end{array}$ & $\begin{array}{l}8-1[45] \\
8-2[45]\end{array}$ & $\begin{array}{l}\text { FCC Code of Federal } \\
\text { Regulations (CFR) } 47 \text {-part } \\
15 \text { subpart h [46] } \\
\text { KDB 416721 } \\
\text { D01 v03 [46] } \\
\text { ANSI C63.10-2013 [46] }\end{array}$ & $\begin{array}{l}\text { Based on FCC and Ofcom [27] } \\
\text { RF } 7545 \text { for WSDB access } \\
{[27]}\end{array}$ & -- & \\
\hline $\begin{array}{l}\text { IEEE 802.11af } \\
\text { (Wi-Fi TVWS) }\end{array}$ & $\checkmark$ & & $\sqrt{ }[27]$ & & $\sqrt{ }[47]$ & $\sqrt{ }[27]$ & Trial only & \\
\hline $\begin{array}{l}\text { IEEE } \\
\text { 802.15.4m } \\
\text { (WPAN) }\end{array}$ & $\checkmark$ & & $\sqrt{ }[4]$ & & $\sqrt{ }[4]$ & $\sqrt{ }[4]$ & - & \\
\hline $\begin{array}{l}\text { IEEE 802.22 } \\
\text { (WRAN) }\end{array}$ & - & & $\sqrt{ }[27]$ & & $\sqrt{ }[27]$ & $\sqrt{ }[27]$ & Trial only & \\
\hline
\end{tabular}

\subsection{White space Devices}

\subsubsection{Singapore}

WSDs are classified into three types in Singapore: the Fixed WSD, Mode II WSD, and Mode I WSD [25]. These devices could also be categorized as either Master or Client WSD. A Master WSD could either be a Fixed or Mode II WSD, while a Client WSD is the Mode I WSD. The Fixed WSD transmits and receives 784 at a fixed location. It chooses a channel to occupy by querying the GLDB. Like the Fixed WSD, the Mode II WSD also decides a channel to use by probing the GLDB. The difference is that the Mode II WSD is portable. TVWS networks must have at least one Fixed WSD or Mode II WSD at any given time. However, the portable Mode I WSD requires a Fixed WSD or a Mode II WSD. It does not access the GLDB 
but instead chooses a channel where it operates through the Fixed or Mode II WSD.

Figure 2 describes how a master and client network [48] operates. Only a master device (either Fixed or
Mode II device) can access the database in this network. The master device provides the client device (Mode I device) with a list of available channels.

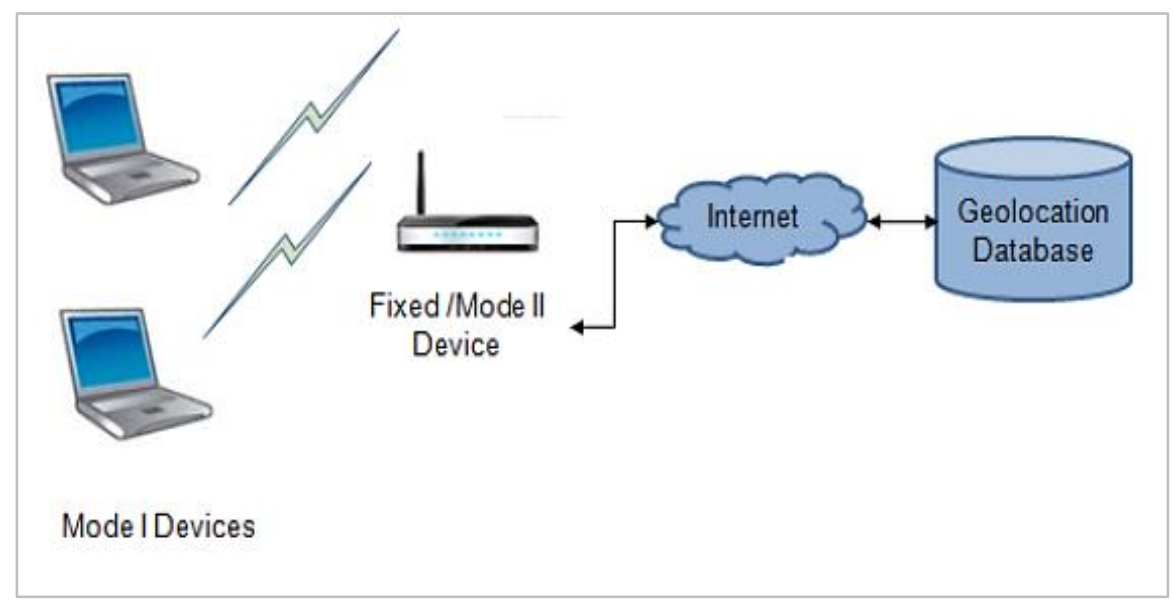

Figure 2 IMDA TVWS network topology [48]

\subsubsection{The United Kingdom}

Ofcom classified their unlicensed devices into two types, namely the Master WSDs and the Slave WSDs. Master WSDs are devices with direct communication links to Ofcom to access a qualifying WSDB. In contrast, Slave WSDs do not have a connection to Ofcom or any WSDB. They depend on Master WSDs to acquire the information needed for operation, such as the frequency and the power parameters [27].

WSDs can also be categorized based on device type, either Type A or Type B. Type A devices are either master or slave WSDs that are purposely designed for fixed use only. These devices are usually the network base stations or the consumer premises equipment. Meanwhile, a Type B device can also be a master or slave WSD. However, it is expected to be mobile or not fixed in a specific location [27]. Type A devices can have integral, dedicated, or extended antennas, while type B devices have only integral or dedicated antennas, with no support for external antennas [27].

WSDs can also be classified based on their Adjacent Channel Leakage Ratios (ACLR). ACLR can be used to determine the limits of out-of-block emissions (spectral leakage) of a WSD using Equation 1.

$$
\begin{aligned}
& P_{\mathrm{OOB}(\mathrm{dBm} /(100 \mathrm{kHz}))} \\
& \leq \max \left\{P_{\mathrm{IB}(\mathrm{dBm} /(8 \mathrm{MHz}))}-\operatorname{ACLR}_{(\mathrm{dB})},-84\right\}
\end{aligned}
$$

Where $P_{\mathrm{IB}}$ is the in-block Effective Isotropic Radiated Power (EIRP) over $8 \mathrm{MHz}$, the out-of-block EIRP spectral density $P_{\mathrm{OOB}}$ can be determined [27]. Consequently, the WSDB can better provide the operating parameters of WSDs, given the type of device and the emission class. Table 2 shows the ACLR for each class. If the WSD does not provide class information, the device is assigned to class 5. Class 5 is the default class for WSD [4].

Figure 3 shows the generic framework of TVWS by Ofcom. The Master WSD first obtains the available WSDB list from Ofcom via the Internet. The Master WSD then inquires the list of free TV channels, together with its power limits, based on its location and device parameters, to the WSDB. The WSDB then responds by providing the necessary parameters for operations. The WSDB computes these parameters based on the data provided by Ofcom [4]. 
Marc Gelian Ante et al.

Table 2 Classification by adjacent channel

\begin{tabular}{llllll}
\hline $\begin{array}{l}\text { Where } P_{\text {Oов }} \text { falls within } \\
\text { the } \boldsymbol{n} \text { th adjacent DTT }\end{array}$ & ACLR $(\mathrm{dB})$ & & & Class 4 & Class 5 \\
\cline { 2 - 6 } & Class 1 & Class 2 & Class 3 & 64 & 43 \\
\hline$n=+/-1$ & 74 & 74 & 74 & 64 & 53 \\
\hline$n=+/-2$ & 79 & 74 & 84 & 74 & 64 \\
\hline$n \geq 3+/-1$ & 84 & 74 & & 64 & \\
\hline
\end{tabular}

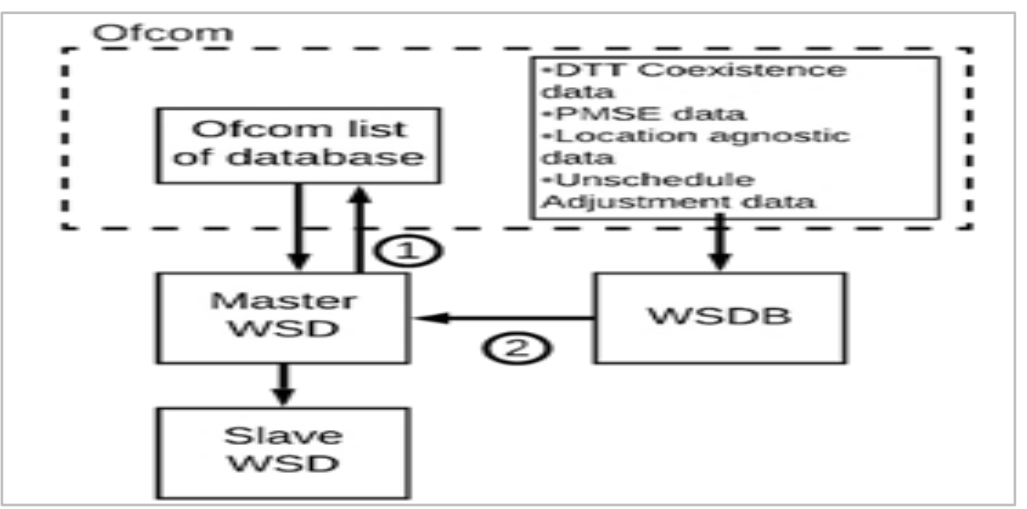

Figure 3 Ofcom TVWS Framework [4]

\subsubsection{The United $S$ tates}

The FCC has two types of unlicensed devices: the fixed device and personal/portable device. There are two main differences between the two: the operating locations and the operating power. Fixed devices have higher power requirements compared to personal/portable devices. In operating locations, a fixed device, as its name implies, simply works in a fixed position. Meanwhile, personal or portable devices' operational site is based on a user's location or mobility [36]. Personal devices can be further categorized into two types [36] or three types [4]. As stated in [36], these two types are Mode I and Mode II. Meanwhile, as stated in [4], the third category type of personal devices is sensing-only.

Fixed devices can use an external antenna with a maximum height of 30 meters above the ground. Furthermore, installing fixed devices is not allowed at a site where the ground Height above the Average Terrain (HAAT) exceeds 250 meters [36].

A Mode I device does not require the use of a GLDB. This device depends on either fixed or Mode II devices to acquire the list of available channels. It does not initiate the formation of the network, nor does it provide a list of available channels to another device [36]. In contrast, a Mode II device can access and utilize GLDB. It can access the GLDB either directly through an Internet connection or by connecting to either a fixed or a Mode II device with access to the Internet.
Additionally, a Mode II device can become a member of a network it initiates and creates. Its operation in this system includes selecting its channel, exchanging information by transmitting or receiving to or from one or more fixed or personal/portable devices. Lastly, a Mode II device can list channels available for a Mode I device [36] to use. A unique signal must be received once every minute by Mode I devices from either fixed or Mode II devices. This unique signal provides the device with a list of currently available channels [27]. Figure 4 shows the process discussed above. The contents of FCC WSDB are stated in FCC CFR part 15 subpart $\mathrm{H}$.

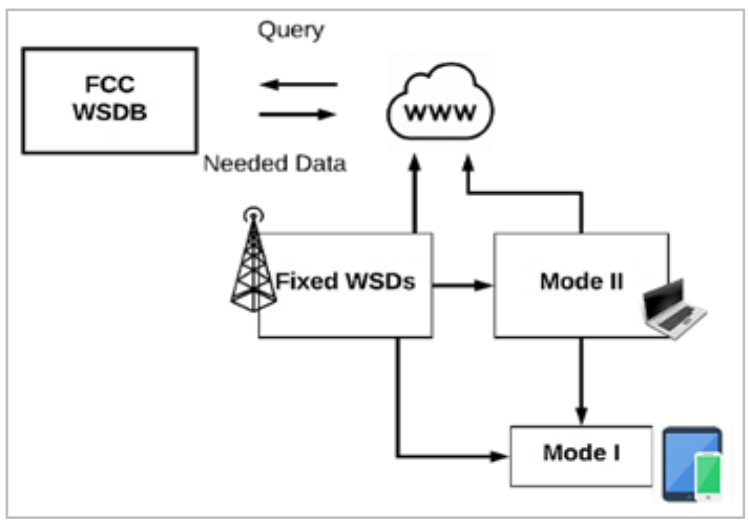

Figure 4 FCC white space devices

All WSDs must sense Advanced Television Systems Committee (ATSC) (digital) TV, NTSC (analog) TV, and wireless microphone signals within certain 
thresholds. For ATSC TV signals, the detection threshold must be $-114 \mathrm{dBm}$ averaged over $6 \mathrm{MHz}$ bandwidth. On the other hand, for NTSC TV signals, the detection threshold is $-114 \mathrm{dBm}$, averaged over $100 \mathrm{kHz}$ bandwidth. Lastly, for low-power auxiliary and wireless microphone signals, the signal threshold is $-107 \mathrm{dBm}$, averaged over $200 \mathrm{kHz}$ bandwidth. Cochannel operation is prohibited for Fixed WSDs if low power auxiliary stations present in the database operate within $1 \mathrm{~km}$ [27].

3.3.4Japan

The trials for TVWS technology conducted by the NICT in London in 2014 have used WSDs based on the standards of Ofcom. In this case, classifications for WSDs used by the NICT are similar to the UK, which are the Master WSD and Slave WSD. These devices can also be classified based on either Type A or Type B. These WSDs may also be classified based on emission class according to European Telecommunications Standards Institute (ETSI) specifications [27]. Besides this way, WSDs can also be classified as either analog or digital [40] or as fixed or mobile [40].

\subsubsection{The Philippines}

During the initial pilot trials of TVWS in the country, base stations and CPEs were set up [39]. The base stations act as the masterdevices, with the CPEs as the client devices. These trials' setup is based on the IEEE 802.22 standard for Wireless Regional Area Network [49].

One of the trials, done as an emergency response to an earthquake, had a one base station setup with three CPEs, as illustrated in Figure 5.

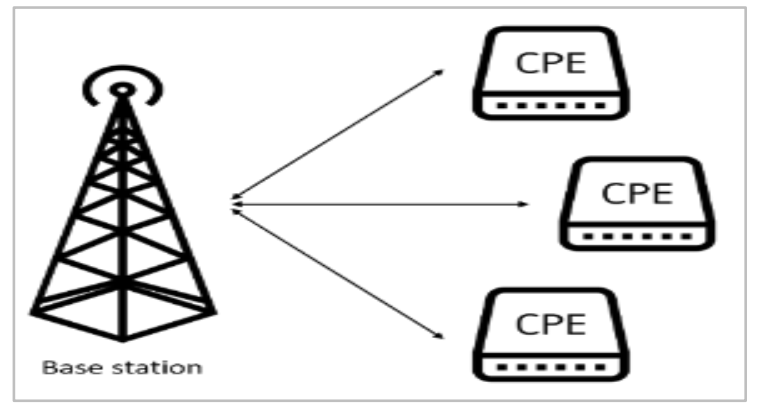

Figure 5 TVWS trial setup [4]

3.4WS frequency range

3.4.1Singapore

WSDs are allowed to operate on a wide range of frequencies in both the VHF band and the UHF band. After the transition from analog to digital television, some channels not previously allocated for TVWS are available for TVWS consumption. Some of the current channels used by TVWS are allotted for other usages [26]. Currently, three channels in the VHF band and twenty-one channels in the UHF band are available for TVWS. Once the transition occurs, six channels and eighteen channels are available from the VHF and UHF bands, respectively.

3.4.2The United Kingdom

Ofcom WSD devices can operate on the white space frequencies from $470 \mathrm{MHz}$ to $606 \mathrm{MHz}$ or the TV channels from 21 to 37 . The devices can also function from $614 \mathrm{MHz}$ to $782 \mathrm{MHz}$ or TV channels from 39 to 59. Ofcom has disallowed the operation of all WSDs in channel 38 to protect the PMSE [4]. Table 3 shows the allowed channels for WSD of Ofcom.

Table 3 Allowable white space frequency

\begin{tabular}{lll}
\hline WSD & Frequency (MHz) & Channel \\
\hline Master WSD [4] & $470-606$ & $21-37$ \\
\cline { 2 - 3 } & $614-782$ & $39-59$ \\
\hline Slave WSD [4] & $470-606$ & $21-37$ \\
\cline { 2 - 3 } & $614-782$ & $39-59$ \\
\hline
\end{tabular}

3.4.3The United States

Fixed devices can occupy any white space frequency [36] except channels 3, 4, and 37 [4]. However, fixed devices are not allowed to operate above $512 \mathrm{MHz}$ (above TV channel 20) if there are adjacent channels to occupied TV channels within the range [36]. Furthermore, Fixed WSDs in metropolitan areas cannot operate co-channel or adjacent channels in channels operated by portable land mobile radio systems (PLMRSs) [27].

However, personal or portable devices can operate in frequencies 512-602 MHz or TV channels from 21 to 36 and $614 \mathrm{MHz}-698 \mathrm{MHz}$, or TV channels from 38 to 51 [36]. Table 4 shows the allowed channels for both WSDs.

Table 4 Allowable white space frequency

\begin{tabular}{lll}
\hline WSD & Frequency & Channel \\
\hline Fixed Devices & $54-60$ & 2 \\
\cline { 2 - 3 }$[27]$ & $76-88$ & $5-6$ \\
\cline { 2 - 3 } & $174-216$ & $7-13$ \\
\cline { 2 - 3 } & $470-512$ & $14-20$ \\
\cline { 2 - 3 } & $512-602$ & $21-35$ \\
\cline { 2 - 3 } & $620-698$ & $39-51$ \\
\hline Personal/Portable & $512-602$ & $21-35$ \\
\cline { 2 - 3 } Permitted [27] & $602-608$ & 36 \\
\cline { 2 - 3 } & $614-620$ & 38 \\
\cline { 2 - 3 } & $620-698$ & $39-51$ \\
\hline
\end{tabular}

3.4.4Japan

As described in [27], NICT was able to comply with Ofcom's white space frequency range. Furthermore, 
the trials of NICT in 2014 showed that the regulatory body could use frequencies from $470 \mathrm{MHz}$ to 790 MHz. As stated in [42], TVWS in Japan can access the frequencies $470 \mathrm{MHz}$ to $710 \mathrm{MHz}$.

\subsubsection{The Philippines}

Not all channels in the UHF band are available for use by TVWS technology in the Philippines. Specifically, only the UHF band below $700 \mathrm{MHz}(470-698 \mathrm{MHz})$ is available for TVWS consumption [43].

\subsection{Bandwidth}

The bandwidth from each country depends on each regulatory body's implementation, with most having bandwidths of 6 or $8 \mathrm{MHz}$. For Japan, the bandwidth can be observed to be at $6 \mathrm{MHz}$ and $8 \mathrm{MHz}$. The trial done in London in 2014 has used a bandwidth of 8 MHz. On the other hand, the experiments held in Tono City, Iwate, Japan, used a bandwidth of $6 \mathrm{MHz}$ [27].

\subsection{Transmission power}

\subsubsection{Singapore}

For the Fixed WSD, the limit for transmission power is $4 \mathrm{~W}$. For a Power Spectral Density (PSD) of 100 $\mathrm{kHz}$, transmission power should not exceed $17.5 \mathrm{dBm}$ EIRP when transmitting in a channel with $7 \mathrm{MHz}$ (VHF), or $17 \mathrm{dBm}$ EIRP when transmitting in a channel with $8 \mathrm{MHz}$ (UHF) [26].

The transmission power for a portable WSD (Mode I and Mode II) is limited to $100 \mathrm{~mW}$. For a PSD of 100 $\mathrm{kHz}$, the transmission power when operating in VHF is limited to $1.55 \mathrm{dBm}$ EIRP and a limit of $0.97 \mathrm{dBm}$ EIRP when operating in the UHF bands [26].

3.6.2The United Kingdom

The determination of the maximum EIRP limits of a WSD is dependent on each frequency located in a geographic pixel on the current location where the WSD is. A geographic pixel is the country's division into $100 \mathrm{~m} \times 100 \mathrm{~m}$ squares or pixels. In this situation, the United Kingdom is divided into over 20 million pixels [4].

The computation of EIRP limits is split between Ofcom and the WSDB. Ofcom computes for the maximum EIRP limits based on the protection of DTT services, cross-border DTT services, PSME operating in channel 38, and services below $470 \mathrm{MHz}$ and above $790 \mathrm{MHz}$. If ad-hoc interference issues occur, Ofcom gets in charge of the unscheduled adjustments for the EIRP limit [4].

The WSDB, on the other hand, is responsible for computing the maximum EIRP limits based on the protection of PMSE and gathering all calculated values of EIRP limits, including the uncertainty in the location of the WSD [4].

The first step for computing the maximum in-band EIRP for the master WSD is to send its horizontal location $(\mathrm{x}, \mathrm{y})$ and location uncertainty $(\Delta \mathrm{x}, \Delta \mathrm{y})$. The WSDB, knowing the location of the master WSD, defines a set of $100 \mathrm{~m} \times 100 \mathrm{~m}$ geographic pixels that cover the area of the WSD. The pixels defined by the WSDB are called candidate pixels. Following this, the WSDB looks up the power limits for each candidate pixel. The power limits are also based on the emission class and the antenna height of the master WSD. Finally, the computed EIRP limit value is the lowest EIRP limit for each available channel for the entire candidate pixels [4].

The location within the coverage of the master WSD and the defined geographical pixels by the WSDB are needed to be determined first to compute for the maximum in-band EIRP of a slave WSD. The WSDB then does a lookup, similar to the case of a master WSD, and the WSDB bases the search on the protection of DTT per available TV channel. The information provided by Ofcom set the power limits. This information depends on the emis sion class of the slave WSD and its antenna height [4]. Table 5 and Table 6 show each channel and its maximum power limit for both types of devices.

3.6.3The United States

The maximum transmit power of fixed WSDs is a maximum EIRP of $4 \mathrm{~W}$. Antennas with a gain of above $6 \mathrm{dBi}$ must reduce the transmit power for EIRP not to exceed $4 \mathrm{~W}$ [27].

In contrast, the maximum EIRP for personal or portable devices is $100 \mathrm{~mW}$ or $20 \mathrm{dBm}$ with a $0 \mathrm{dBi}$ antenna gain. However, if the pers onal/portable device operates adjacent to a TV station or license station, the maximum EIRP is limited to $40 \mathrm{~mW}$. When possible, power should generally be adjusted to less than the maximum power permitted [27].

A level below $55 \mathrm{~dB}$ of the operating channel is the restriction for out-of-band (OOB) emission for all WSDs operating in the first adjacent channel; additionally, the measurement of OOB is for a 100 $\mathrm{kHz}$ bandwidth [27].

Fixed devices have power spectral density limits of $16.7 \mathrm{~mW}(12.2 \mathrm{dBm})$. Meanwhile, the threshold for personal/portable devices is $1.67 \mathrm{~mW}$ (2.2 dBm). Furthermore, personal/portable devices operating in 
the adjacent channels have a limit of $0.7 \mathrm{~mW}(-1.8$ $\mathrm{dBm})$. As with the OOB emissions, the power spectral density value measurement is for a $100 \mathrm{kHz}$ bandwidth [27].

Table 5 Maximum power in dBm limits for type A devices [27]

\begin{tabular}{|c|c|c|c|c|c|}
\hline Channels & Class 1 & Class 2 & Class 3 & Class 4 & Class 5 \\
\hline 21 & 30 & 30 & 20 & 10 & -1 \\
\hline 22 & 35 & 30 & 30 & 20 & 9 \\
\hline 23 & 36 & 30 & 30 & 30 & 20 \\
\hline 24 & 36 & 36 & 36 & 36 & 30 \\
\hline 34 & 36 & 36 & 34 & 34 & 22 \\
\hline 35 & 33 & 33 & 25 & 25 & 12 \\
\hline 36 & 29 & 22 & 25 & 15 & 1 \\
\hline 37 & 24 & 21 & 15 & 5 & -9 \\
\hline 38 & - & - & - & - & - \\
\hline 39 & 24 & 21 & 15 & 5 & -9 \\
\hline 40 & 29 & 22 & 25 & 15 & 1 \\
\hline 41 & 33 & 30 & 25 & 25 & 12 \\
\hline 42 & 36 & 36 & 34 & 34 & 22 \\
\hline
\end{tabular}

\subsubsection{Japan}

The experiment conducted by Japan in Tono City, Iwate prefecture, in 2013 involves the use of IEEE 802.22 and IEEE 802.11af. The trial investigates the coexistence of the 802.22 and 802.11af standards. 802.22 providing a long-distance backhaul link, with IEEE 802.11af expanding the wireless access area supplied by the backhaul link. The experiment deployed radio equipment for a long-range backhaul link, from Tono City to Takashimizu and Sadato, with Tono city serving as the center. The distance from the Tono city to Takashimizu and from Takashimizu to Sadato is $6.3 \mathrm{~km}$ and $12.7 \mathrm{~km}$, respectively. The experiment shows that IEEE 802.22 requires $2.9 \mathrm{~W}$ in a $300 \mathrm{~m}$ ground height and $20 \mathrm{~m}$ antenna height for the multihop networking. Meanwhile, IEEE 802.11af requires $0.97 \mathrm{~W}$ for a $710 \mathrm{~m}$ ground height and $12 \mathrm{~m}$ antenna height [27].
As stated in [41], antenna power is based on the bandwidth used by the WSD for broadcasting. A full segment type, occupying $5.7 \mathrm{MHz}$, can have a power of $10 \mathrm{~mW}$ to $130 \mathrm{~mW}$, depending on certain conditions such as the radius or distance separation and causing interference to adjacent channels [41]. With $468 \mathrm{kHz}$ bandwidth, the one segment type only has a maximum antenna power of $50 \mathrm{~mW}$. Based on [40], transmit power is based on the type of system or method used. For the analog method, $10 \mathrm{~mW}$ of power can be used, while $50 \mathrm{~mW}$ can be used for the digital method. 3.6.5The Philippines

For the base station, a minimum RF transmit power of $+28 \mathrm{dBm}$ is required. CPEs, on the other hand, have a lower minimum transmit power requirement, which is $+26 \mathrm{dBm}[43]$.

Table 6 Maximum power limits in dBm for Type B devices [27]

\begin{tabular}{|c|c|c|c|c|c|}
\hline & Class 1 & Class 2 & Class 3 & Class 4 & Class 5 \\
\hline 21 & 30 & 30 & 20 & 10 & -1 \\
\hline 22 & 35 & 30 & 30 & 20 & 9 \\
\hline 23 & 36 & 30 & 30 & 30 & 20 \\
\hline 24 & 36 & 36 & 36 & 36 & 30 \\
\hline 34 & 36 & 36 & 31 & 31 & 22 \\
\hline 35 & 30 & 30 & 22 & 22 & 12 \\
\hline 36 & 26 & 22 & 22 & 12 & 1 \\
\hline 37 & 21 & 21 & 12 & 2 & -9 \\
\hline 38 & - & - & - & - & - \\
\hline 39 & 21 & 21 & 12 & 2 & -9 \\
\hline 40 & 26 & 22 & 22 & 12 & 1 \\
\hline 41 & 30 & 30 & 22 & 22 & 12 \\
\hline 42 & 36 & 36 & 31 & 31 & 22 \\
\hline
\end{tabular}


3.7Safety standards

Table 1 shows some of the safety standards adopted by each of the regulatory bodies. Each manual contains the required operating procedures or parameters' value set by each regulatory agency to operate in its governing country. These standards need to be compiled by any seller, researcher, or entity involved in the operation of TVWS.

3.7.1Singapore

The WSDs used are tested based on electromagnetic compatibility (EMC) emissions and electrical safety. Limits for EMC emissions are defined in ETSI EN 301 489-1, which explains the EMC standards requirement for radio equipment and services, or in IEC CISPR 32, which identifies the EMC standards requirement for multimedia equipment. The standards for electrical safety, on the other hand, are defined in the IEC
60950-1, setting the criteria for the safety of information technology, or IEC 62368-1, defining the standards for audio/video and information and communication technology equipment [26].

3.7.2The United Kingdom

TR 100 028-1 and TR 100 028-2 are two parts of the technical report with the title of "Electromagnetic compatibility and Radio spectrum Matters "; Uncertainties of mobile radio equipment characteristics." The technical report references relevant standards containing the methods for calculating measurement uncertainty for assessing radio equipment performance [45]. Table 7 shows a recent list of companies that commercializes TVWS in different countries.

Table 7 Commercialization and Application of TVWS

\begin{tabular}{llll}
\hline Company & Application & Improvements & Locations \\
\hline NuRan/ Globe [50] & Wireless backhaul & Alternative backhaul trial & Trials in the Philippines \\
\hline AMMBR [51] & Broadband & $\begin{array}{l}\text { TVWS with blockchain } \\
\text { capable routers }\end{array}$ & $\begin{array}{l}\text { Trials in the US, UK, and } \\
\text { Europe }\end{array}$ \\
\hline Tilson and Microsoft [52] & Broadband & $\begin{array}{l}\text { Airband initiative of } \\
\text { Microsoft }\end{array}$ & Rural parts of America \\
\hline ARK and Microsoft [53] & $\begin{array}{l}\text { Broadband and Over-the- } \\
\text { top (OTT) }\end{array}$ & $\begin{array}{l}\text { Coexistence of ATSC 3.0 } \\
\text { and TVWS }\end{array}$ & Trials in Texas \\
& $\begin{array}{l}\text { Unmanned drones for } \\
\text { monitoring }\end{array}$ & Real-time video transmission & Singapore \\
\hline Whizspace [54] & Broadband & $\begin{array}{l}\text { 4G/5G solution combined } \\
\text { with TVWS }\end{array}$ & $\begin{array}{l}\text { Rural areas Ohio and } \\
\text { Kentucky }\end{array}$ \\
\hline $\begin{array}{l}\text { Watch Communications } \\
\text { 55] }\end{array}$ & Broadband & $\begin{array}{l}\text { Point to Multipoint Solution } \\
\text { (PtMP) }\end{array}$ & US and UK \\
\hline RADWIN [56] & Database administrator & Canada \\
\hline Red Technologies [57] & GLDB & $\begin{array}{l}\text { Internet Service Provider } \\
\text { (ISP) network Rollout }\end{array}$ & $\begin{array}{l}\text { Commercial } \\
\text { communities in England }\end{array}$ \\
\hline Redline and Fibairo [58] & Broadband & &
\end{tabular}

\subsubsection{The United $S$ tates}

FCC CFR 47 part 15 subpart $\mathrm{h}$ is a section of "Rules and Regulations for Title 47" found on the FCC's website. Part 15 section is for radio frequency devices, and subpart $\mathrm{H}$ is for white space devices. Subpart $\mathrm{H}$ contains definitions of white space devices, methods such as interference avoidance, and other needed operation conditions.

KDB 416721 D01 v03, or the "Certifications Test Procedures for White Space Devices Authorized Under Subpart H of the Part 15 Rules," can also be found on the FCC's website. The purpose of this document is for the guidance for WSD measurements and validation procedures.

Lastly, the document ANSI C63.10-2013 contains the procedure for testing the compliance of unlicensed wireless transmitters.
3.7.4Japan

NICT's database is based on the published guidelines and specifications of Ofcom and FCC. NICT's database gives the calculated operational parameters for WSDs [27].

Another protocol followed by the WSD is the RFC 7545 or the Protocol to Access White-Space (PAWS). The Internet Engineering Task Force (IETF) provides this protocol, which defines the managing spectrum sharing using the databases and providing channel availability.

\subsection{Commercialization of TVWS technology}

In this section, the commercialization of TVWS is reported based on news articles and is compared based on the deployment type and use scenario. Most of the deployments are in the countries that already provided the regulations in the use of TVWS. Service providers 
are partnering with companies that provide WSD elements and antennas and use TVWS as a solution. Use cases are typical to provide broadband access in rural areas $[51,52,56,58]$. On the other hand, TVWS was used for data trans mis sion to trans mit live footage captured by unmanned drones for island monitoring [54] since the TVWS bands have good propagation characteristics in challenging and long-distance terrains.

Improvements are also compared based on the combined technologies like the coexistence of ATSC 3.0 to provide OTT media services [53]. TVWS can also be used as an alternative backhaul for mobile communication [50,55], especially in rural areas with rough terrains that are hard to deploy fiber optics or microwave links, requiring Line-of-Sight to operate. In [57], the GLDB administrator was approved and can soon help ease the deployment of TVWS in the said country. Also, the comparison shows that different countries are already accepting the use of TVWS and provides a cost-effective solution with numerous application that improves existing wireless communication systems.
3.9Recent field trials and simulations of TVWS Due to the demand for spectrum resources as wireless technologies emerge, the use of TVWS can be a potential solution to bridge the digital divide. The use of TVWS is not limited to providing broadband access and profitability. Challenges arise in the use of TVWS, such as interference to the primary users, as can be seen in Table 1, where the safest way to use TVWS is to use a GLDB. Hence, field trials have been reported to measure the spatial and temporal occupancies of VHF and UHF bands. A survey of occupancy measurement techniques has been reported in [7] that provided researchers with methods for quantifying available bands. Quantitative measurements of available whitespaces based on locations are also carried out to develop a GLDB for each location. In countries with the unregulated use of TVWS, trials and measurements are being reported to accelerate the regulations. Moreover, trials are being made to achieve policy reforms in these countries. Table 8 shows a comparison of recent trials, surveys, and methodology that helps improve the utilization of TVWS technology in different aspects.

Table 8 Schemes for improving TVWS applications

\begin{tabular}{lll}
\hline Techniques & Set-up & Potential Application \\
\hline LTE using TVWS [59] & Measurement and trial & Policy reform and use of CCN \\
\hline Protection Contour [60] & Calculations & Interference protection \\
\hline Keep out of distance[61] & GLDB development & GLDB \\
\hline BPLC+TVWS [62] & Simulation sy stem & IoT Networks \\
\hline TV Viewership Dynamics [63] & $\begin{array}{l}\text { Measurement and propagation } \\
\text { models }\end{array}$ & Spectrum availability \\
\hline WISER [64] & Measurement and sensing & Indoor localization \\
\hline MISEN [65] & Measurement and Sensing & Indoor localization \\
\hline LMMSE and OMP [66] & Channel Estimation & Standard Compliance \\
\hline Tresholding 80\% method (ITU-R) [67] & Measurement and assesment & Maritime Vehicular Communication \\
\hline [68] & Survey & Applications of TVWS \\
\hline [69] & Survey & Networking in TVWS \\
\hline 5G+HAP+TVWS [70] & Simulation sy stem & Mobile Networks \\
\hline Variation of approaches [71] & Measurement and Experiments & Sy stematic Approach \\
\hline
\end{tabular}

The method in [60] provided a calculation of the keepout distance to avoid interference from the contour of the active TV broadcast of four different standards. Furthermore, this method was also utilized to develop a GLDB using calculated keep-out of distance around 1.6 2.52 km from the service contour of Primary User (PU) in rural areas in Cebu Philippines [61]. Measured occupancy of UHF Band (Band 71) was done in [59] to open up and opportunistically TVWS and uses the band for Long-Term Evolution (LTE) and develop Community-based Cellular Network (CCN). On the other hand, Broadband Power Line Communication
(BPLC) in conjunction with TVWS was simulated in [62] called a high throughput white BPLC with the use of BPLC for the broadband use specifically of IoT. The simulation shows a $29 \%$ increase with wider coverage of BPLC. An alternative approach in [63], framework, and simulations are made to get the capacity of the available TVWS by considering the TV viewership as the primary users. The authors developed a micro and macro model based on viewership analytics and provide a minimum increase of 3.8 in spectrum availability. For the indoor localization where GPS performs poorly, TVWS is 
proposed to be used as an alternative. However, determining the whitespace indoors poses another challenge. In [64], the authors proposed a White-s pace Indoor Spectrum EnhanceR (WISER) system that accurately identifies $30-50 \%$ indoor white spaces. Additionally, A prototype is developed in [65] also for indoor localization of TVWS using the Alternating Direction Method of Multipliers (ADMM). Estimating the channel state information, the authors in [66] utilized Linear Minimum Mean Square Error (LMMSE) and Orthogonal Matching Pursuit (OMP) for realistic channel state information where LMMSE attains the $1-2 \mathrm{~dB}$ better performance than OMP.

Maritime vehicular communication also requires a long-range capable system. Measurements in [67], the Nautical Highway for maritime vehicular communication using the cumulative distribution of receive power and maximum contiguous bandwidth, showed the number of available TVWS channels. Recently, a survey of applications of TVWS was presented in [68] that discussed the applications of TVWS such as broadband wireless access, femtocell networks, cellular-Wireless Local Area Network (WLAN), smart-grid network, and indoor localization. To achieve the applications, networking in TVWS is also considered, where a survey of networking techniques in the TVWS is investigated in [69]. Due to the stringent demands of standards such as 5G, different approaches are also considered where TVWS can be used as an alternative link. In [70], a proposed scheme uses TVWS as the link to enable 5G using High Altitude Platforms (HAP) that provide services to rural areas. This scheme can potentially reduce infrastructure costs and improve mobility in providing mobile services. Lastly, a systematic approach of the GLDB and the spectrum sensing approach is reported in [71], where several factors may affect the potency of this approach.

Table 8 summarizes the discussions mentioned above where different approaches and simulations are employed to improve TVWS, which has numerous potential for augmenting wireless systems. Also, the table shows techniques which, if implemented, leads to different benefits to existing systems. Complete list of abbreviations is shown in Appendix I.

\section{Conclusions}

Although having pilot tests and implementations in different countries worldwide, an internationally accepted standard and regulation of TVWS technology have not yet been published. At the time of writing this paper, among the countries of interest, only Singapore, the United States, and the United Kingdom have a defined set of regulations for the use of TVWS and WSDs in their respective countries. Japan, continuously developing TVWS technology, has yet to establish a specific regulation. The same can be said about the Philippines as well.

One thing in common about the implementations done by the different countries in this work is their spectrum identification method. The adoption of WSDB for this purpose has proven it to be the most efficient way for WSDs to know the operation parameters they should follow. The WSDs implemented by each country are also similar to each other, having master and slave devices. In this aspect, WSDs in Singapore and the US are identical, having adopted a Fixed, Mode II, and Mode I classification for their devices. Japan and the UK are also similar, both implementing the Type A and Type B classifications for their WSDs. Another classification for WSDs exists in the UK, based on their ACLR. The Philippines, however, having no established regulation for WSDs, adopts 802.22 standards for the classification of WSDs: the base station and the CPEs.

The frequency range and the bandwidth used for TVWS vary, depending on each country's broadcasting regulation. It also depends on their policies on the allocation of the radio spectrum. A unique attribute for the US not present in the other implementations exists, however. Besides the frequency ranges available for both fixed and portable devices, some channels are only available for fixed devices. Some channels are only available for the use of portable devices.

For the transmission power, similarities again arise in Singapore and the US's implementations, both having the same power limits on their WSDs. Power limits in the UK depend on both the class of the device and its channel of operation.

Singapore, the US, and the UK implement various safety standards, with no two countries implementing the same standard. However, Japan adopts the US and the UK standards, with an additional standard for WSDB access. We can highlight the differences in the implementation of TVWS between the UK and the US. Even though both regulatory bodies utilize WSDB, Ofcom's database provides the necessary operational parameters such as EIRP to its WSDs throughout their operation. In contrast, the FCC's operational parameters are already defined in the WSDB, and therefore no further computation is 
needed. In this case, the WSD provides its operating parameters to the WSDB, so this would mean that the WSD should maintain these parameters throughout its operation. Another significant difference between the implementations of Ofcom and the FCC is the determination of the contour area. Ofcom utilized geographic pixels computed and processed by the WSDB, while FCC uses the F $(50,50)$ and F $(90,50)$ for mapping.

Recent trials, simulations, and techniques, each with different use cases reported in the literature, are surveyed in this paper. These trials show that TVWS could be a promising solution along with challenges that need to be addressed. The implementation complexity is a massive challenge in deploying TVWS, as seen in the literature, due to the spatial and temporal constraints. Nevertheless, the reported literature on the trials shows approaches and methods to minimize these constraints and help improve the implementation of this technology.

TWWS technology has yet to see widespread implementation, being still in the testing phases for some countries. Most countries are transitioning from analog to digital broadcast, freeing up a large amount of the spectrum. With having more unused TV frequencies in the TV bands, TVWS could be more utilized. As an emerging technology, having defined regulations for the use of TVWS would assure investors of the stability and the future of the technology, as this technology could significantly contribute to societal improvements. Finally, this paper extends a survey and comparisons of regulations, WSD, commercialization, trials, and simulations to accelerate the development, international regulations, and deployment of TVWS.

\section{Acknowledgment}

The De La Salle University and the Sumitomo Foundation are acknowledged for supporting this work.

\section{Conflicts of interest}

The authors have no conflicts of interest to declare.

\section{References}

[1] Chowdhury M, Biswas A. Wireless communication: theory and applications. Cambridge University Press; 2017.

[2] https://www.prnewswire.com/news-releases/global-tvwhite-space-spectrum-market-2020-2027-transitionto-digital-tv-paves-the-way - rising-emphasis-on-iotenthuses-301214857.html. Accessed 26 April 2021.

[3] Haykin S. Cognitive radio: brain-empowered wireless communications. IEEE Journal on Selected Areas in Communications. 2005; 23(2):201-20.
[4] Oh SW, Ma Y, Tao MH, Peh E. TV white space: the first step towards better utilization of frequency spectrum. John Wiley \& Sons; 2016.

[5] Act E, No ED. Second report and order and memorandum opinion and order. ET Docket. 2008.

[6] Baykas T, Kasslin M, Cummings M, Kang H, Kwak J, Paine R, et al. Developing a standard for TV white space coexistence: technical challenges and solution approaches. IEEE Wireless Communications. 2012; 19(1):10-22.

[7] Islam MH, Koh CL, Oh SW, Qing X, Lai YY, Wang C, et al. Spectrum survey in Singapore: occupancy measurements and analy ses. In international conference on cognitive radio oriented wireless networks and communications 2008 (pp. 1-7). IEEE.

[8] López-benítez M, Umbert A, Casadevall F. Evaluation of spectrum occupancy in Spain for cognitive radio applications. In VTC spring 69th vehicular technology conference 2009 (pp. 1-5). IEEE.

[9] Mishra AK, Johnson DL. White space communication: advances, developments and engineering challenges. Springer; 2014.

[10] Oluwafemi IB, Femijemilohun OJ, Oluwasola SL, Owolabi IE. Investigation of error bounds of empirical path loss models at UHF band in Ondo State, Nigeria. ARPN Journal of Engineering and Applied Sciences. 2018; 13(9):3172-81.

[11] Ye Y, Wu D, Shu Z, Qian Y. Overview of LTE spectrum sharing technologies. IEEE Access. 2016; 4:8105-15.

[12] IEEE computer society LAN/MAN standards committee. IEEE standard for information technology telecommunications and information exchange between sy stems-local and metropolitan area networksspecific requirements part 11: wireless lan medium access control (MAC) and physical layer (PHY) specifications. IEEE Std 802.11^. 2007.

[13] https://standards.ieee.org/standard/802_22-2019.html. Accessed 26 April 2021.

[14] Cerro G, Miele G, Hislop R, Holland O, Mody A. IEEE 802.15. 22.3 spectrum characterization and occupancy sensing application testbed. IEEE Instrumentation \& Measurement Magazine. 2020; 23(9):58-64.

[15] Elmasry GF. IEEE standard for radio interface for white space dynamic spectrum access radio systems supporting fixed and mobile operation. John Wiley \& Sons Ltd: 2020.

[16] IEEE Standards Association. IEEE Standard for architectural building blocks enabling network-device distributed decision making for optimized radio resource usage in heterogeneous wireless access networks. IEEE Std. 1900;2009:C1-119.

[17] https://www.ecma-international.org/publications-andstandards/standards/ecma-392/. Accessed 26 April 2021.

[18] https://www.wirelesswhitespace.org/. Accessed 26 April 2021.

[19] Holland O, Ping S, Aijaz A, Chareau JM, Chawdhry P, Gao Y, et al. To white space or not to white space: that is the trial within the ofcom TV white spaces pilot. In 
international symposium on dynamic spectrum access networks 2015 (pp. 11-22). IEEE.

[20] Holland O. Some are born with white space, some achieve white space, and some have white space thrust upon them. IEEE Transactions on Cognitive Communications and Networking. 2016; 2(2):178-93.

[21] Ko HT, Lee CH, Lin JH, Chung K, Chu NS. Television white spaces: learning from cases of recent trials. International Journal of Digital Television. 2014; 5(2):149-67.

[22] www.whizpace.com/media-and-awards. Accessed 26 April 2021.

[23] Bañacia AS, Caluyo FS. An overview of TV white space use cases in the Philippines. Korean society of electronics engineers conference. 2017 (pp. 385-9).

[24] Carpio M. TV white space for development programs in the Philippines: implications and challenges. In Asia conference on society, education, and technology. 2015.

[25] www.imda.gov.sg//media/Imda/Files/Inner/PCDG/Consultations/201306 17_whitespace/ExplanatoryMemo.pdf. Accessed 26 April 2021.

[26] www.imda.gov.sg/-/media/imda/files/regulationlicensing-and-consultations/ictstandards/telecommunication-standards/radiocomms/imda-ts-wsd.pdf?la=en. Accessed 26 April 2021.

[27] Holland O, Bogucka H, Medeisis A. Opportunistic spectrum sharing and white space access: the practical reality. John Wiley \& Sons; 2015.

[28] www.philstar.com/business/technology/2016/06/13/15 92211/dost-icto-transitions-department-ict. Accessed 26 April 2021.

[29] https://dict.gov.ph/cordoba-takes-oath-as-reappointedntc-commissioner/. Accessed 26 April 2021.

[30] https://ntc.gov.ph/wp-content/uploads/2017/MC/MC02-04-2017.pdf. Accessed 26 April 2021.

[31] Chatterjee S, Roy JS. Optimization of spectrum sensing in cognitive radio by demand based adaptive genetic algorithm. ARPN Journal of Engineering and Applied Sciences. 2017; 12(23):6794-802.

[32] Senthilkumar B, Srivatsa SK. Wideband spectrum sensing using adaptive neuro fuzzy inference sy stem in cognitive radio networks. ARPN Journal of Engineering and Applied Sciences.2015; 10(15):405560

[33] Swetha N, Sastry PN, Rao YR. Spectrum sensing analy sis using PSD based entropy detection of DVB-T signal. ARPN Journal of Engineering and Applied Sciences.2012; 9(12):2854-7.

[34] Nekovee M. A survey of cognitive radio access to TV white spaces. Ultra-modern telecommunications \& workshops, ICUMT. 2009. IEEE

[35] Dionísio R, Ribeiro J, Marques P, Rodriguez J. Combination of a geolocation database access with infrastructure sensing in TV bands. EURASIP Journal on Wireless Communications and Networking. 2014:114.
[36] Ramjee R, Roy S, Chintalapudi K. A critique of fcc's tv white space regulations. GetMobile: Mobile Computing and Communications. 2016; 20(1):20-5.

[37] ky odonewsprwire.jp/prwfile/release/M 101744/201505 019858/_prw_OA1fl_v7qyK5Mc.pdf. Accessed 26 April 2021.

[38] amchamphilippines.eventbank.com/resources/protecte d/organization/851/event/1 1463/bbdf1764-3580-4e53a346-c66dd1a2d7f4.pdf. Accessed 26 April 2021.

[39] spectrumfutures.org/wpcontent/uploads/2015/04/Casambre-Update-on-TVWhite-Spaces-in-the-Philippines.pdf?c8da21. Accessed 26 April 2021.

[40] Abe T. 4-2 about the use of specified radio microphone. The Journal of the Institute of Image Information and Television. 2015; 69(5):403-7.

[41] www.soumu.go.jp/main_sosiki/kenkyu/whitespace/02 kiban09_03000156.html. Accessed 26 April 2021.

[42] Bureau S. Ministry of internal affairs and communications. Government of Japan. 2010.

[43] i.gov.ph/wp-content/uploads/2015/06/Bid-Docs_TVWhite-Space-_second-bidding_FINAL_checkedv2.pdf. Accessed 26 April 2021.

[44] www.tele.soumu.go.jp/horei/reiki_honbun/a72073000 1.html. Accessed 26 April 2021.

[45] https://www.etsi.org. Accessed 26 April 2021.

[46] fccid.io/2ABCU-50911-U/Test-Report/11719486E1V2-FCC-Part-15H-RF-Database-Report-TestReport-Part 1-3604046.html. Accessed 26 April 2021.

[47] Cheng Y, Wang X, Xiao L. An efficient MAC layer access protocol for white space standard IEEE 802.11af. In international conference on multimedia and image processing 2017 (pp. 320-4). IEEE.

[48] Singapore ID. Proposed regulatory framework for TV white space operations in the VHF/UHF bands. Consultation Paper Issue by the Info-Communications Development Authority of Singapore. 2013.

[49] Gupta S, Malagar V. IEEE 802.22 standard for regional area networks. In international conference on next generation computing and information systems 2017 (pp. 126-30). IEEE.

[50] https://nuranwireless.com/news-nl/tvws-globetelecom-philippines/. Accessed 26 April 2021.

[51] https://www.prnewswire.co.uk/news-releases/ammbrreveals-technology-for-long-range-wirelessconnectivity-up-to-8-km-689651641.html. Accessed 26 April 2021.

[52] https://www.prnewswire.com/newsreleases/microsoft-and-tilson-team-up-to-expandaccess-to-broadband-internet-in-rural-communitiesacross-america-300943228.html. Accessed 26 April 2021.

[53] https://www.businesswire.com/news/home/201910140 05725/en/ARK-Multicasting-and-Microsoft-

Announce-Agreement-for-Rural-Broadband-andDistributed-Cloud-Services. Accessed 26 April 2021.

[54] https://www.straitstimes.com/tech/unmanned-dronesfor-monitoring-singap ores-southern-islands-on-trial. Accessed 26 April 2021. 
[55] https://www.businesswire.com/news/home/202006080 05702/en/Watch-Communications-LaunchesMicrosoft-Airband-Initiative-in-Indiana-and-Illinois. Accessed 26 April 2021.

[56] https://www.radwin.com/press-room/announcingcommercial-availability-of-radwin-outlandtm-ptmptv-white-space-solution-for-rural-broadband-access/. Accessed 26 April 2021.

[57] https://www.prnewswire.com/news-releases/redtechnologies-launches-tvws-database-service-incanada-301259595.html. Accessed 26 April 2021.

[58] https://www.newswire.ca/news-releases/redlinecommunications-aligns-with-fibairo-to-tacklebroadband-challenges-in-the-united-kingdom861066493.html. Accessed 26 April 2021.

[59] Hilario CA, Barela MC, De Guzman MF, Loquias RT, Raro RV, Quitayen JJ, et al. LokaLTE: $600 \mathrm{MHz}$ community LTE networks for rural areas in the Philippines. In global humanitarian technology conference 2020 (pp. 1-8). IEEE.

[60] Foo YL. Keep-out distance of the IEEE 802.11 af sy stem from digital TV broadcast contour. In TENCON 2017 (pp. 1185-8). IEEE.

[61] Pilapil DY, Bañacia AS. Development and implentation of a TV white space geolocation database for IEEE 802.11 af system using the ITU-R P. 1411 recommendation. In world symposium on communication engineering 2019 (pp. 53-7). IEEE.

[62] Heggo M, Sun S, Zhu X, Huang Y. TV white space regulated broadband power line communication for point-to-multipoint downlink IoT networks: a standard perspective. IEEE Internet of Things Journal. 2018; 6(4):6226-36.

[63] Zhao Z, Vuran MC, Batur D, Ekici E. Shades of white: impacts of population dy namics and TV viewership on available TV spectrum. IEEE Transactions on Vehicular Technology. 2019; 68(3):2427-42.

[64] Ying X, Zhang J, Yan L, Zhang G, Chen M, Chandra R. Exploring indoor white spaces in metropolises. In proceedings of the annual international conference on mobile computing \& networking 2013 (pp. 255-66).

[65] Zheng X, YiF, Liu D, Wu F, Chen G. MISEN: a mobile indoor white space exploration method. In international conference on communications 2019 (pp. 1-6). IEEE.

[66] Başaran M, Macit MC, Şenol H, Erküçük S. Realistic channel estimation of IEEE 802.11af systems in TV white space. IEEE Transactions on Vehicular Technology . 2020; 69(10):11066-76.

[67] Loquias RT, Hilario CA, De Guzman MF, Marciano JJ. Quantitative assessment of tv white space in the western Philippine nautical highway. In international symposium on dynamic spectrum access networks 2019 (pp. 1-8). IEEE.

[68] Zhang W, Yang J, Guanglin Z, Yang L, Yeo CK. TV white space and its applications in future wireless networks and communications: a survey. IET Communications. 2018; 12(20):2521-32.
[69] Rahman M, Saifullah A. A comprehensive survey on networking over TV white spaces. Pervasive and Mobile Computing. 2019.

[70] Katzis K, Mfupe L, Hussien HM. Opportunities and challenges of bridging the digital divide using $5 \mathrm{G}$ enabled high altitude platforms and TVWS spectrum. In international conference on communications and networking 2020 (pp. 1-7). IEEE.

[71] Mauwa H, Bagula A, Zennaro M, Pietrosemoli E, Lysko A, Brown TX. Systematic analysis of geolocation and spectrum sensing as access methods to TV white space. In ITU kaleidoscope: ICTs for a sustainable world 2016 (pp. 1-8). IEEE.

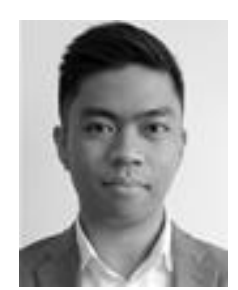

Marc Gelian Ante received his B.Sc. degree in Electronics Engineering (ECE) from De La Salle University, Philippines, in 2017. Currently, he is taking up the M.Sc. ECE degree at the same university. For his undergraduate thesis, his group developed a microcontroller-based power monitoring and switching device for appliances. His professional and research interests include Intelligent Systems and the Internet of things (IoT).

Email: marc_gelian_ante@dlsu.edu.ph

James Agustin Molina received his B.Sc. degree in Electronics Engineering (ECE) from Mapúa University, Philippines, in 2017. Currently, he is taking up the M.Sc. ECE degree at De La Salle University, Philippines.

Email: james_molina@dlsu.edu.ph

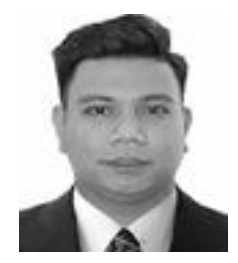

Emmanuel Trinidad received the B.Sc. degree in Electronics Engineering (ECE) from Angeles University Foundation, Philippines in 2016. Currently, he is taking up the M.Sc. ECE degree at De La Salle University, Philippines.

Email: emmanuel_trinidad@dlsu.edu.ph

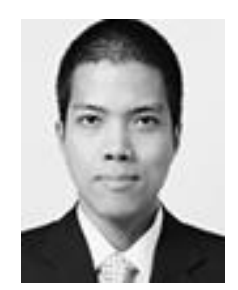

Lawrence Materum received the B.Sc. degree in Electronics and Communications Engineering with honors from Mapúa Institute of Technology (now Mapúa University), the M.Sc. degree in Electrical Engineering major in Computers and Communications from the University of the Philippines Diliman through an Analog Devices Fellowship, and the Ph.D. degree in international development engineering (major in electrical/electronics engineering) from Tokyo Institute of Technology through a MEXT Scholarship.

Email: materuml@dlsu.edu.ph 
Marc Gelian Ante et al.

Appendix I

\begin{tabular}{|c|c|c|}
\hline S.No. & Abbreviation & Description \\
\hline 1 & $4 \mathrm{G}$ & Fourth-Generation Mobile Networks \\
\hline 2 & $5 \mathrm{G}$ & Fifth-Generation Mobile Networks \\
\hline 3 & ACLR & Adjacent Channel Leakage Ratio \\
\hline 4 & ADMM & $\begin{array}{l}\text { Alternating Direction Method of } \\
\text { Multipliers }\end{array}$ \\
\hline 5 & ATSC & $\begin{array}{l}\text { Advanced Television Systems } \\
\text { Committee }\end{array}$ \\
\hline 6 & BPLC & Broadband Powerline Communication \\
\hline 7 & $\mathrm{CCN}$ & Community-based Cellular Network \\
\hline 8 & CFR & Code of Federal Regulations \\
\hline 9 & $\mathrm{CPE}$ & Customer Premise Equipment \\
\hline 10 & DICT & $\begin{array}{l}\text { Department of Information and } \\
\text { Communications Technology }\end{array}$ \\
\hline 11 & DOST & Department of Science and Technology \\
\hline 12 & DSA & Dynamic Spectrum Access \\
\hline 13 & DTT & Digital Terrestrial Television \\
\hline 14 & EIRP & Effective Isotropic Radiated Power \\
\hline 15 & EMC & Electromagnetic Compatibility \\
\hline 16 & ETSI & $\begin{array}{l}\text { European Telecommunications } \\
\text { Standards Institute }\end{array}$ \\
\hline 17 & FCC & Federal Communications Commission \\
\hline 18 & GLDB & Geolocation Database \\
\hline 19 & HAAT & Height above the Average Terrain \\
\hline 20 & HAP & High Altitude Platform \\
\hline 21 & ICTO & $\begin{array}{l}\text { Information and Communications } \\
\text { Technology Office }\end{array}$ \\
\hline 22 & IDA & $\begin{array}{l}\text { Info-Communications Development } \\
\text { Authority }\end{array}$ \\
\hline 23 & IETF & Internet Engineering Task Force \\
\hline 24 & IMDA & $\begin{array}{l}\text { Infocomm Media Development } \\
\text { Authority }\end{array}$ \\
\hline 25 & IoT & Internet of Things \\
\hline 26 & ISP & Internet Service Provider \\
\hline 27 & LMMSE & Linear Minimum Mean Square Error \\
\hline 28 & LTE & Long-Term Evolution \\
\hline 29 & MIC & $\begin{array}{l}\text { Ministry of Information and } \\
\text { Communications }\end{array}$ \\
\hline 30 & NICT & $\begin{array}{l}\text { National Institute of Information and } \\
\text { Communications }\end{array}$ \\
\hline 31 & NTC & $\begin{array}{l}\text { National Telecommunications } \\
\text { Commission }\end{array}$ \\
\hline 32 & Ofcom & Office of Communications \\
\hline 33 & OMP & Orthogonal Matching Pursuit \\
\hline 34 & OOB & Out-of-Band \\
\hline 35 & OTT & Over-the-Top \\
\hline 36 & PAWS & Protocol to Access White-Space \\
\hline 37 & PMSE & Program Making and Special Events \\
\hline 38 & PRISMA & $\begin{array}{l}\text { Preferred Reporting Items for } \\
\text { Systematic Reviews and Meta-Analyses }\end{array}$ \\
\hline 39 & PSD & Power Spectral Density \\
\hline 40 & PtMP & Point to Multipoint \\
\hline 41 & $\mathrm{PU}$ & Primary User \\
\hline 42 & QoS & Quality of Service \\
\hline 43 & TSAC & $\begin{array}{l}\text { Telecommunications Standards } \\
\text { Advisory Committee }\end{array}$ \\
\hline 44 & TVWS & Television White Space \\
\hline 45 & UHF & Ultra High Frequency \\
\hline 46 & VHF & Very High Frequency \\
\hline 47 & WLAN & Wireless Local Area Network \\
\hline 48 & WSD & White Space Device \\
\hline 49 & WSDB & White Space Database \\
\hline
\end{tabular}

